\title{
Correction to: Endoscopic surgical treatment for rhinogenic contact point headache: systematic review and meta-analysis
}

\author{
Antonino Maniaci ${ }^{1}$ (D) - Federico Merlino ${ }^{1}$ - Salvatore Cocuzza ${ }^{1}$ - Giannicola lannella ${ }^{2,3} \cdot$ Claudio Vicini $^{3}$. \\ Giovanni Cammaroto ${ }^{3}$. Jérome R. Lechien ${ }^{4,5,6,7} \cdot$ Christian Calvo-Henriquez $^{8} \cdot$ Ignazio La Mantia $^{1}$
}

Published online: 7 May 2021

(c) The Author(s) 2021

\section{Correction to: European Archives of Oto-Rhino-Laryngology https://doi.org/10.1007/s00405-021-06724-6}

In the original publication of the article, one of the author name was published incorrectly as "Jérome Lechien". The correct name is "Jérome R. Lechien".

The original article was updated.

Open Access This article is licensed under a Creative Commons Attribution 4.0 International License, which permits use, sharing, adaptation, distribution and reproduction in any medium or format, as long as you give appropriate credit to the original author(s) and the source, provide a link to the Creative Commons licence, and indicate if changes were made. The images or other third party material in this article are included in the article's Creative Commons licence, unless indicated otherwise in a credit line to the material. If material is not included in the article's Creative Commons licence and your intended use is not permitted by statutory regulation or exceeds the permitted use, you will need to obtain permission directly from the copyright holder. To view a copy of this licence, visit http://creativecommons.org/licenses/by/4.0/.

The original article can be found online at https://doi.org/10.1007/ s00405-021-06724-6.

Antonino Maniaci

tnmaniaci29@gmail.com

1 Department of Medical and Surgical Sciences and Advanced Technologies "GF Ingrassia", ENT Section, ENT

Department of University of Catania, Via Santa Sofia, 95100 Catania, Italy

2 Department of 'Organi Di Senso', University "Sapienza”, Rome, Italy

3 Department of Head-Neck Surgery, Otolaryngology, Head-Neck, and Oral Surgery Unit, Morgagni Pierantoni Hospital, Forlì, Italy

4 Research Committee of the Young Otolaryngologists, International Federations of ORL Societies, Paris, France
5 Department of Human Anatomy and Experimental Oncology, School of Medicine, UMONS Research Institute for Health Sciences and Technology, University of Mons, Mons, Belgium

6 Department of Otorhinolaryngology-Head and Neck Surgery, CHU Saint-Pierre, School of Medicine, Université Libre de Bruxelles, Brussels, Belgium

7 Department of Otolaryngology-Head and Neck Surgery, Foch Hospital, (University of Paris-Saclay), Paris, France

8 Task Force COVID-19 of the Young-Otolaryngologists of the International Federations of Oto-Rhino-Laryngological Societies (YO-IFOS), Department of Otolaryngology, Hospital Complex of Santiago de Compostela, Santiago de Compostela, Spain 